\title{
A PROTEÇÃO DE DADOS PESSOAIS NO CONTEXTO DA ECONOMIA INFORMACIONAL: DESAFIOS REGULATÓRIOS DO MARKETING COMPORTAMENTAL
}

\author{
THE PERSONAL DATA PROTECTION WITHIN THE INFORMATIONAL \\ ECONOMY CONTEXT: REGULATORY CHALLENGES OF BEHAVIORAL \\ MARKETING

\begin{abstract}
PROTECCIÓN DE DATOS PERSONALES EN EL CONTEXTO DE LA ECONOMÍA DE LA INFORMACIÓN: DESAFÍOS REGULATORIOS DEL MARKETING CONDUCTUAL
\end{abstract}

\author{
Cíntia Rosa Pereira de Lima \\ http://orcid.org/0000-0001-8175-0724 / http:/ / lattes.cnpq.br/8616609272212862 / cintiar@usp.br \\ Faculdade de Direito de Ribeirão Preto (FDRP - USP) \\ Ribeirão Preto, SP, Brasil
}

\begin{abstract}
RESUMO
A corrida pela monetização de dados pessoais foi iniciada por importantes players da economia informacional. Amazon, Google e Facebook são alguns exemplos de como os algoritmos de personalização podem ser utilizados de maneira extremamente lucrativa. Estas técnicas são constantemente aprimoradas, utilizando machine learning, collaborative filtering e Inteligência Artificial. Neste contexto de intenso e constante desenvolvimento, cabe à Autoridade Nacional de Proteção de Dados regular e complementar a Lei Geral de Proteção de Dados, além de fiscalizar o seu correto cumprimento. Neste artigo, objetiva-se evidenciar algumas ferramentas para o enforcement da LGPD no cenário do capitalismo de vigilância, tais como os "Códigos de Boas Práticas" e a regulação e fiscalização por parte da ANPD. Empregou-se nessa pesquisa, o método dedutivo, partindo-se da constatação da hipervulnerabilidade dos titulares de dados pessoais e o legítimo desenvolvimento econômico, conclui-se que deve se chegar a um consenso harmonizando os interesses em jogo, tendo em vista a recente aprovação do Regulamento do Processo de Fiscalização e do Processo Administrativo Sancionador pela ANPD, que enfatiza a regulação responsiva.
\end{abstract}

Palavras-chave: Autoridade Nacional de Proteção de Dados; capitalismo de vigilância; direito de revisar as decisões automatizadas; Lei Geral de Proteção de Dados Pessoais (LGPD).

\section{ABSTRACT}

The personal data monetization race was started by important players in the information economy. Amazon, Google and Facebook are some examples of how personalization algorithms can be used in an extremely profitable way. These techniques are constantly improved, using machine learning, collaborative filtering and Artificial Intelligence. In this context of intense and constant development, it is up to the Brazilian National Data Protection Authority to regulate and complement the Brazilian General Data Protection Law, in addition to overseeing its correct compliance. This article aims to highlight some tools for the enforcement of LGPD in the scenario of surveillance capitalism, such as the "Good Practices Code" and the regulation and inspection by the ANPD. It was applied the deductive method, based on the verification of the hypervulnerability of the personal data subject and the legitimate economic development, to conclude that a consensus must be reached by harmonizing the interests at stake, in view of the recent approval of the Regulation of the Inspection Process and the Sanctioning Administrative Process by ANPD, which emphasizes responsive regulation.

Keywords: Brazilian National Data Protection Authority; surveillance capitalism; right to review automated decisions; Brazilian General Data Protection Law. 


\section{RESUMEN}

La carrera por la monetización de datos personales fue iniciada por importantes actores de la economía de la información. Amazon, Google y Facebook son algunos ejemplos de cómo los algoritmos de personalización se pueden utilizar de forma extremadamente rentable. Estas técnicas se mejoran constantemente, utilizando aprendizaje automático, filtrado colaborativo e Inteligencia Artificial. En este contexto de intenso y constante desarrollo, corresponde a la Autoridad Nacional de Protección de Datos brasileña regular y complementar la Ley General de Protección de Datos de Brasil, además de velar por su correcto cumplimiento. E artículo busca destacar algunas herramientas para la aplicación de la LGPD en el escenario del capitalismo de vigilancia, como los "Códigos de Buenas Prácticas" y la regulación e inspección por parte de la ANPD. En esta investigación se utilizó el método deductivo, basado en la verificación de la hipervulnerabilidad de los titulares de datos personales y el legítimo desarrollo económico, se concluye que se debe llegar a un consenso armonizando los intereses en juego, en vista de la reciente aprobación del Reglamento del Proceso de Inspección y el Proceso Administrativo Sancionador por parte de la ANPD, que enfatiza la regulación receptiva.

Palabras clave: Autoridad Nacional de Protección de Datos brasileña; capitalismo de vigilancia; derecho a revisar decisiones automatizadas; Ley General de Protección de Datos de Carácter Personal de Brasil (LGPD).

\section{SUMÁRIO}

INTRODUÇÃO; 1 OS PERCALÇOS À PROTEÇÃO DE DADOS PESSOAIS CONSOANTE AS TENDÊNCIAS DA ECONOMIA INFORMACIONAL; 2 O MARKETING COMPORTAMENTAL E DIRETO NO CONTEXTO DA PROTEÇÃO DE DADOS PESSOAIS; 2.1 Capitalismo de vigilância e a circulação transfronteiriça dos dados pessoais; 2.2 Capitalismo informacional sustentável e os Códigos de Boas Práticas em matéria de proteção de dados; 3 OS PERIGOS DOS PERFIS CONSTRUídOS DE MANEIRA AUTOMATIZADA; 4 A ATUAÇÃO DA AUTORIDADE NACIONAL DE PROTEÇÃO DE DADOS PESSOAIS PARA UMA ECONOMIA INFORMACIONAL SUSTENTÁVEL; CONCLUSÃO; REFERÊNCIAS.

\section{INTRODUÇÃO}

A economia informacional está estruturada a partir de tecnologias utilizadas para monetizar informações que identifiquem ou possam identificar as pessoas. No contexto das redes sociais, as "pegadas digitais", entendidas como todos os rastros deixados pelos usuários, tais como curtidas, não-curtidas, compartilhamentos, dentre outros, revelam informações utilizadas para construir o perfil da pessoa, apontando suas predileções. Assim, este é um campo fértil para o desenvolvimento e o aprimoramento da ferramenta de marketing comportamental, ou seja, os anúncios publicitários ou propagandas de cunho político são personalizados a fim de otimizar o consumo de produtos e serviços, bem como de informações.

Neste sentido, a Lei Geral de Proteção de Dados (LGPD) ${ }^{1}$ traz uma série de princípios e regras que limitam o tratamento dos dados pessoais. Um dos pontos destacados neste trabalho é o art. 20 da LGPD, ou seja, o direito assegurado ao titular de dados pessoais de revisar as decisões automatizadas com base no perfil que os algoritmos de personalização possam apontar

\footnotetext{
1 BRASIL. Lei $n^{\circ} 13.709$ de 14 de agosto de 2018. Lei Geral de Proteção de Dados Pessoais (LGPD). In: Diário Oficial da República Federativa do Brasil, Brasília, DF, 15 ago. 2018.
} 
ISSN 1981-3694

(DOI): $10.5902 / 1981369464767$

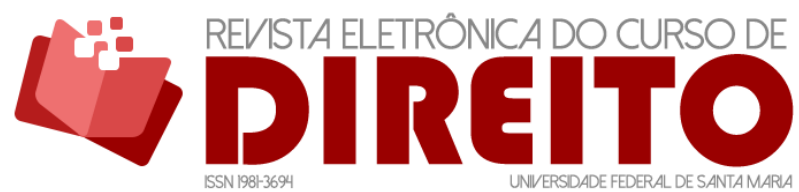

A PROTECC̃̃O DE DADOS PESSOAIS NO CONEXTO DA ECONOMIA INFORMACIONAL: DESAFIOS REGULATÓRIOS DO MARKETING COMPORTAMENTAL

sobre a pessoa. A LGPD impõe a obrigação ao controlador de disponibilizar de forma clara e adequada os critérios e os procedimentos utilizados para a construção destes perfis.

0 problema investigado neste artigo é sobre a efetividade deste direito no cenário da economia informacional. Portanto, os objetivos deste trabalho são: analisar as características da economia informacional, com destaque para os algoritmos de personalização; apontar os desafios à efetiva proteção de dados pessoais diante do "capitalismo de vigilância"; indicar mecanismos para se atingir a maior eficiência deste direito a partir de uma atuação multissetorial, ressaltando os "Códigos de Boas Práticas", além da atuação da Autoridade Nacional de Proteção de Dados (ANPD) para se construir o melhor cenário para um desenvolvimento sustentável da economia informacional.

Para tanto, utiliza-se o método dedutivo, pelo qual colocadas algumas premissas apontadas acima, a de que a economia informacional utiliza dados pessoas de maneira lucrativa e a de que o direito à proteção de dados pessoais é um direito fundamental, pretende-se chegar à conclusão sobre ferramentas eficazes para a proteção do titular de dados, reequilibrando os interesses em confronto.

Assim, o texto pontua os desafios da proteção de dados pessoais no contexto da economia informacional, exemplificando alguns modelos de negócio que utilizam estes algoritmos de personalização. Em seguida, destaca os interesses envolvidos no denominado “capitalismo de vigilância”, caracterizada a hipervulnerabilidade dos titulares de dados pessoais, bem como algumas técnicas do marketing comportamental. Então, o artigo evidencia o direito à revisão das decisões automatizadas e da construção dos perfis online, com base no que dispõe a LGPD, inspirada no Regulamento Geral de Proteção de Dados da União Europeia. Ao final, o artigo explora como a Autoridade Nacional de Proteção de Dados (ANPD) tem a missão institucional, seja por meio de auditorias ao fiscalizar os agentes de tratamento de dados, seja por meio de regulamentos ao estabelecer padrões tecnológicos em prol da proteção dos titulares de dados pessoais, de assegurar o enforcement dos princípios e direitos assegurados pela LGPD diante dos desafios da economia informacional e do capitalismo de vigilância a fim de se atingir um capitalismo informacional sustentável. 


\section{OS PERCALÇOS À PROTEÇÃO DE DADOS PESSOAIS CONSOANTE AS TENDÊNCIAS DA ECONOMIA INFORMACIONAL}

A economia informacional, cujo embrião remonta à década de 1970, nos Estados Unidos, onde foram desenvolvidos a ARPANET ${ }^{2}, \mathrm{ALOHANET}^{3}$ e $\mathrm{SATNET}^{4}$, apresenta muitos desafios à tutela efetiva dos titulares de dados pessoais. Em linhas gerais, destaca-se a utilização dos dados pessoais como valiosa moeda de troca no contexto do capitalismo informacional. Neste sentido, Eli Pariser ${ }^{5}$ realça que todas as informações sobre as pessoas são verdadeiras mercadorias, pois o constante monitoramento das aplicações de Internet resulta em um volume de dados que são utilizados por empresas de maneira integrada para que os serviços e os produtos oferecidos cheguem ao usuário identificado como interessado nestes serviços e produtos. Além disso, estas informações são utilizadas, de forma até mais lucrativa, para sussurrar aos usuários destas aplicações estes serviços e produtos, implantando necessidades de consumo a partir de técnicas de marketing ainda mais agressivas.

Constata-se uma mudança substancial das ideias embrionárias da Internet, seja para o desenvolvimento científico, seja para fins militares, o fato é que hoje esta tem sido uma ferramenta poderosa no direcionamento de preferências, personalizando as notícias que os usuários da Internet acessam, a forma pela qual eles tomam decisões políticas e a maneira pela qual estes usuários pensam e consomem.

\footnotetext{
2 Advanced Research Projects Agency Network, grupo criado a partir do Advanced Research Projects Agency (conhecido pela sigla ARPA), em 07 de fevereiro de 1958, liderado pelo professor de psicologia experimental do Instituto de Massachusetts - MIT, Joseph Carl Robenett Licklider, além de sua equipe Wes Clark, Bob Taylor, Larry Roberts e Leonard Leinrock, cujo objetivo era construir um sistema de interconexão sem fio entre computadores. Cf. MURRAY, Andrew. Information Technology Law: the law and society. Oxford: Oxford University Press, 2010. p. 19.

${ }^{3}$ Essa foi uma rede construída por um Professor do Havaí, em 1969, que conectou sete computadores em 7 ilhas diferentes do arquipélago. $\mathrm{E}$ as informações eram transmitidas via comunicação semelhante à dos rádios. $O$ interessante desta rede é que a informação era transmitida ainda que houvesse interferências, quando a informação seria reenviada por outro canal de radiofrequência. Diferente da ARPANET que somente permitia a transmissão desde que o canal de comunicação estivesse livre e preparado para tal tráfego de dados. Cf. LIMA, Cíntia Rosa Pereira de. Autoridade Nacional de Proteção de Dados e a Efetividade da Lei Geral de Proteção de Dados. São Paulo: Almedina, 2020. p. 47.

${ }^{4}$ Esta rede é caracterizada pela transmissão via satélite.

${ }^{5}$ PARISER, Eli. The filter bubble: how the new personalized web is changing what we read and how we think. Nova York: Penguin Book, 2011. pp. 45 - 46: "What all of this means is that your behavior is now a commodity, a tiny piece of a market that provides a platform for the personalization of the whole Internet. We're used to thinking of the Web as a series of one-to-one relationships: You manage your relationship with Yahoo separately from your relationship with your favorite blog. But behind the scenes, the Web is becoming increasingly integrated. Businesses are realizing that it's profitable to share data. Thanks to Acxiom and the data market, sites can put the most relevant products up front and whisper to each other behind your back." (grifo nosso).
} 
ISSN 1981-3694

(DOI): $10.5902 / 1981369464767$

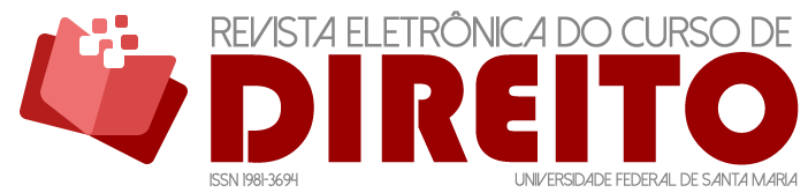

A PROTEÇÃO DE DADOS PESSOAIS NO CONEXTO DA ECONOMIA INFORMACIONAL: DESAFIOS REGULATÓRIOS DO MARKETING COMPORTAMENTAL

CíNTIA Rosa PEREIRA DE LIMA

Não foi por acaso que esta ferramenta foi utilizada de maneira nefasta para enviesar o processo democrático nas eleições presidenciais norte-americanas e mesmo no plebiscito do Brexit, no Reino Unido. No primeiro caso, conhecido como Cambrigde Analytica, esta instituição inglesa de análise de dados utilizou dados locacionais e informações compartilhadas na rede social Facebook para captar potenciais eleitores. Para tanto, a empresa teve acesso aos dados de 87 milhões de contas de usuários cadastrados na plataforma. Em comunicado publicado em 16 de março de $2018^{6}$, o Facebook afirmou que a Cambridge Analytica recebeu dados de usuários do aplicativo conhecido como This is Your Digital Live, desenvolvido por Aleksandr Kogan, professor e pesquisador em neurociência cognitiva e comportamental da Universidade de Cambridge, que calcula as predileções de personalidade dos usuários cujos dados são submetidos ao sistema, utilizado como um teste de personalidade.

O usuário deste aplicativo podia utilizá-lo a partir de sua conta no Facebook, solicitando o acesso ao seu perfil e locais visitados, bem como o acesso aos dados de seus amigos. Os dados foram coletados com o consentimento dos usuários, mas por Aleksandr Kogan, como agente de tratamento, que não poderia ter realizado o uso compartilhado dos dados com a Cambridge Analytica, sem o consentimento dos titulares, dada a ausência de outra base legal para o tratamento de dados pessoais. Quanto ao acesso dos dados pessoais dos amigos dos perfis coletados, o Facebook permitia a realização dessa prática, dentre seus termos de serviço, desde que consentida pelo usuário, o que foi proibido apenas em 2015. A Cambridge Analytica utilizou os dados obtidos à operacionalização de estratégias on-line, como em prol da campanha eleitoral de Donald Trump, que contratou os serviços da instituição, em 2016, para identificar eleitores e segmentá-los com anúncios customizados aos seus diferentes perfis. ${ }^{7}$

O segundo caso, conhecido como o plebiscito sobre o Brexit, que desencadeou a saída do Reino Unido da União Europeia. Este caso caracteriza-se pela utilização de social bots no Twitter para divulgar conteúdo que influenciou na votação do plebiscito. A suspeita se iniciou tendo em vista o alto tráfego de mensagens no Twitter sobre o tema, muitas destas contas da

\footnotetext{
${ }^{6}$ GREWAL, Paul. Suspending Cambridge Analytica and SCL Group from Facebook. Facebook Newsroom, 16 março 2018. Disponível em: https://newsroom.fb.com/news/2018/03/suspending-cambridge-analytica/ . Acesso em: 15 de fev. 2021.

${ }^{7}$ LIMA, Cíntia Rosa Pereira de Lima; PEROLI, Kelvin. Direito Digital: compliance, regulação e governança. São Paulo: Quartier Latin, 2019. pp. 86 - 89.
} 
ISSN 1981-3694

(DOI): $10.5902 / 1981369464767$

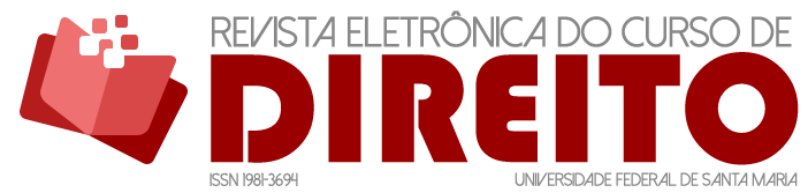

A PROTEÇÃO DE DADOS PESSOAIS NO CONEXTO DA ECONOMIA INFORMACIONAL: DESAFIOS REGULATÓRIOS DO MARKETING COMPORTAMENTAL

CíNTIA Rosa PEREIRA DE LIMA

rede social postavam centenas de mensagens sobre o tema por dia com relevantes indícios de automação, detectados a partir da análise da linguagem. ${ }^{8}$

Estes fatos revelam uma técnica muito utilizada, qual seja, a construção de perfis dos usuários de redes sociais e de outras aplicações de Internet, construídos a partir da coleta indiscriminada das informações que identificam ou possam identificar essa pessoa. Neste sentido, a Lei Geral de Proteção de Dados, Lei n. 13.709, de 14 de agosto de 2018, traz importantes regras a serem observadas o que tende a coibir os abusos na construção automatizada dos perfis. Isso gera preocupação aos big players, já acostumados a desenvolver suas atividades lucrativas sem as cautelas impostas pela LGPD, cuja vigência foi alvo de controvérsias, marcada pela atuação de fortes lobbies empresariais, que tentaram postergar a entrada em vigor da lei, que entrou em vigor parcialmente em 18 de setembro de 2020, ${ }^{9}$ sendo que em agosto de 2021, passou a vigorar em sua plenitude, com a possibilidade de aplicar sanções administrativas pela ANPD. Assim, a partir de 28 de outubro de 2021, com a aprovação do Regulamento do Processo de Fiscalização e do Processo Administrativo Sancionador (Resolução CD/ANPD n. $\left.1^{\circ}\right)^{10}$

No entanto, deve-se atentar ao enforcement da LGPD no contexto da economia informacional. Esta, segundo Manuel Castells ${ }^{11}$, tem um marco espacial determinado para seu surgimento, ou seja, os Estados Unidos, mais especificamente o Estado da Califórnia (onde a primeira transmissão wireless de pacotes de dados entre computadores foi concretizada) e um marco temporal, os anos 1990, porque somente a partir da facilitação das interfaces entre computador e ser humano é que a Internet foi difundida realmente.

\footnotetext{
${ }^{8}$ BASTOS, Marco T; MERCEA, Dan. The Brexit Botnet and User-Generated Hyperpartisan News. Social Science Computer Review, vol. 37, issue 1, 2019. Disponível em: https: //journals.sagepub.com/doi/pdf/10.1177/0894439317734157, acesso em: 15 de fev. 2021.

${ }^{9}$ A LGPD entrou em vigor parcialmente no dia 18 de setembro de 2020, quando o Presidente Jair Bolsonaro sancionou a Lei n. 14.058, de 17/09/2020, publicada no Diário Oficial da União no dia 18/09/2020, retirando os artigos que pretendiam postergar a vigência da LGPD para maio de 2021. Assim, entende-se que a LGPD está em vigor a partir da vigência da Lei n. 14.058/2020. Entretanto, as sanções previstas na lei são aplicáveis somente a partir de $1^{\circ}$ de agosto de 2020 , porque a Lei n. ${ }^{\circ} 14.010$, de 10 de junho de 2020, que estabelece normas que compõem o denominado "Regime Jurídico Emergencial e Transitório das relações jurídicas de Direito Privado (RJET)" no período da pandemia do novo coronavírus, determinou no art. 20 a prorrogação da vigência dos artigos 52, 53 e 54 da LGPD a partir de $1^{\circ}$ de agosto de 2021.

${ }^{10}$ BRASIL. Autoridade Nacional de Proteção de Dados (ANPD). Resolução CD/ANPD n. 1, de 28 de outubro de 2021. Aprova o Regulamento do Processo de Fiscalização e do Processo Administrativo Sancionador no âmbito da Autoridade Nacional de Proteção de Dados. Disponível em: https://www.in.gov.br/web/dou//resolucao-cd/anpd-n-1-de-28-de-outubro-de-2021-355817513, acesso em: 06 de nov. 2021.

11 The rise of the network society: the information age: economy, society and culture. Cornwall: Blackwell Publishers, 2000. V. 1. pp. 147 - 148.
} 
ISSN 1981-3694

(DOI): $10.5902 / 1981369464767$

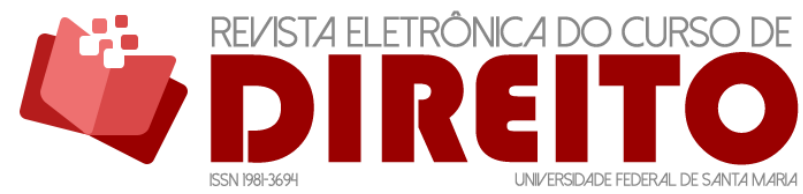

A PROTEÇÃO DE DADOS PESSOAIS NO CONEXTO DA ECONOMIA INFORMACIONAL: DESAFIOS REGULATÓRIOS DO MARKETING COMPORTAMENTAL

CíNTIA Rosa PEREIRA DE LIMA

Em síntese, a economia informacional é caracterizada por ser informacional, porque a produtividade e competitividade depende da capacidade de gerar, processar e aplicar de maneira eficiente as informações baseadas no conhecimento científico e tecnológico; global porque a produção, a distribuição e o consumo são organizados em nível global e com a interligação entre vários agentes da economia; interconectada ("networked", na expressão de Manuel Castells) porque as novas condições socioeconômicas impõem a interconexão em redes entre as empresas. Quanto mais sólida for tal network, mais competitiva a produção desses agentes econômicos será.

Importante frisar que a sociedade informacional vai muito além da Internet, engloba toda a forma de comunicação como alertado por Greice Patricia Fuller e José Luiz Bátiz Lopez. ${ }^{12}$

Nota-se que as aplicações de Internet dão uma falsa ideia de que os serviços seriam gratuitos. Na verdade, tal "gratuidade", no início da WWW, visava facilitar e incentivar a utilização desses programas, o que de fato ocorreu. Assim, hoje, muitos aplicativos oferecem suas vantagens "gratuitamente", com o objetivo de conquistar cada vez mais usuários. Porém, aqui se aplica o dito "there is no free lunch", porque a informação é um valor em si mesmo nessa economia informacional, por isso, quanto mais informações pessoais os grandes provedores de aplicativos têm, maior lucro e maior poder econômico eles terão. Esta lógica pode ser resumida em uma frase de John Perry Barlow ${ }^{13}$ : “A distribuição não-comercial de informações aumenta a venda de infomações comerciais. Abundância gera abundância.”

Neste sentido, cabe destacar que o Superior Tribunal de Justiça ${ }^{14}$, em reiteradas decisões, solidificou o entendimento de que os serviços prestados na Internet, quando gratuitos, não desvirtuam a relação de consumo, na medida em que se constata a remuneração "indireta" do fornecedor por meio de anúncios publicitários. Além do ganho advindo dos anúncios publicitários, soma-se a alta lucratividade a partir do tratamento de dados pessoais

12 FULLER, Greice Patricia; LOPEZ, José Luiz Bátiz. Empresa, Drechos Humanos y Sociedad de la Información. Revista Eletrônica do Curso de Direito da Universidade Federal de Santa Maria, vol. 14, n. 2, e33710, maio./ago. 2019. ISSN 1981-3694. DOI: http://dx.doi.org/10.5902/1981369433710 . Disponível em: https://periodicos.ufsm.br/revistadireito/article/view/33710 Acesso em: $15 \mathrm{de} \mathrm{fev.} 2021$.

13 "Noncommercial distribution of information increases the sale of comercial information. Abundance breeds abundance." (Tradução pela RECDUFSM). The Next: Economy of Ideas. Wired 8.10. 06 páginas. Disponível em: https://www.wired.com/2000/10/download/ , acesso em 12 de fev. 2021. p. 03.

${ }^{14}$ BRASIL. SUPERIOR TRIBUNAL DE JUSTIÇA. REsp 1186616/MG, Rel. Ministra NANCY ANDRIGHI, TERCEIRA TURMA, julgado em 23/08/2011, DJe 31/08/2011: "RISCO INERENTE AO NEGÓCIO. INEXISTÊNCIA. CIÊNCIA DA EXISTÊNCIA DE CONTEÚDO ILÍCITO. RETIRADA IMEDIATA DO AR. DEVER. DISPONIBILIZAÇÃO DE MEIOS PARA IDENTIFICAÇÃO DE CADA USUÁRIO. DEVER. REGISTRO DO NÚMERO DE IP. SUFICIÊNCIA. 1. A exploração comercial da internet sujeita as relações de consumo daí advindas à Lei $n^{\circ} 8.078 / 90$. 2. 0 fato de o serviço prestado pelo provedor de serviço de internet ser gratuito não desvirtua a relação de consumo, pois o termo "mediante remuneração", contido no art. $3^{\circ}, \S 2^{\circ}$, do CDC, deve ser interpretado de forma ampla, de modo a incluir o ganho indireto do fornecedor. [...]" 
ISSN 1981-3694

(DOI): $10.5902 / 1981369464767$

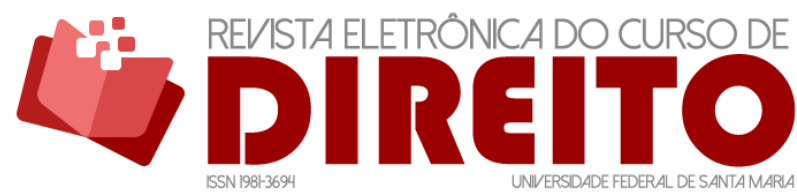

A PROTEÇÃO DE DADOS PESSOAIS NO CONEXTO DA ECONOMIA INFORMACIONAL: DESAFIOS REGULATÓRIOS DO MARKETING COMPORTAMENTAL

CíNTIA Rosa PEREIRA DE LIMA

especialmente utilizados para uma técnica publicitária mais sofisticada: o marketing comportamental.

Portanto, pode-se entender a LGPD como uma ferramenta para reequilibrar a relação jurídica entre os agentes de tratamento de dados e os titulares de dados pessoais, estes últimos são hipervulneráveis haja vista sua constante exposição às práticas de tratamento de dados para as mais diversas finalidades, muitas vezes, desconhecidas. Por isso, a LGPD impõe princípios para o tratamento de dados pessoais (art. $6^{\circ}$ ), dentre os quais está justamente o princípio da finalidade (inc. I), segundo o qual o tratamento de dados somente se justifica para propósitos legítimos, específicos, explícitos e informados ao titular de dados, além dos princípios da adequação, necessidade, livre acesso, qualidade dos dados, transparência, segurança, prevenção, não discriminação, responsabilidade e prestação de contas.

Além dos princípios, a LGPD elenca as bases legais para que o tratamento de dados seja lícito no art. $7^{\circ}$ (dados pessoais) e no art. 11 (dados pessoais sensíveis), ou seja, os agentes de tratamento devem demonstrar a existência de uma das bases legais para que possa realizar qualquer operação com dados pessoais.

\section{MARKETING COMPORTAMENTAL E DIRETO NO CONTEXTO DA PROTEÇÃO DE DADOS PESSOAIS}

A fim de compreender o marketing comportamental e dirigido, importante retomar os primeiros passos da corrida pela monetização dos dados pessoais. Destaca-se, em 1994, o modelo da Amazon.com, qual seja, sugerir livros para as pessoas conforme suas preferências. Como nos tempos antigos, em que o livreiro conhecia todos os seus clientes e sabia quais livros gostariam de adquirir. Entretanto, diferentemente do livreiro, esse modelo de negócio passou a utilizar uma ferramenta muito mais eficiente: machine learning. ${ }^{15}$ Para tanto, a Amazon passou implementou um sistema denominado collaborative filtering, a partir da análise de como as pessoas regiam aos e-mails (enviados gratuitamente para um número indefinido de pessoas). Se essas pessoas interagiam substancialmente, abrindo o e-mail, ficavam no topo da lista; os $e$ mails deletados ou não abertos ficavam no final da lista. A partir destas informações e com o uso

\footnotetext{
${ }^{15}$ ROUSE, Margaret. What Is Machine Learning. WHATIS.COM. Disponível em: http://whatis.techtarget.com/definition/machine-learning, acesso em: 10 de fev. 2021. "Machine learning is a type of artificial intelligence (Al) that provides computers with the ability to learn without being explicitly programmed. Machine learning focuses on the development of computer programs that can teach themselves to grow and change when exposed to new data."
} 
ISSN 1981-3694

(DOI): $10.5902 / 1981369464767$

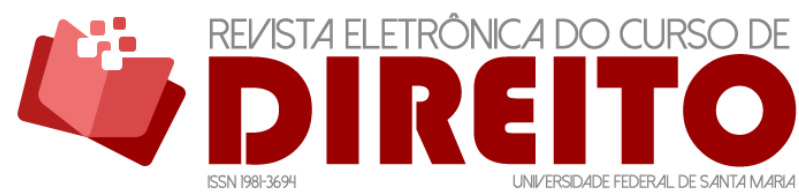

A PROTEÇÃO DE DADOS PESSOAIS NO CONEXTO DA ECONOMIA INFORMACIONAL: DESAFIOS REGULATÓRIOS DO MARKETING COMPORTAMENTAL

CíNTIA Rosa PEREIRA DE LIMA

de aprendizado de máquina, era possível detectar com certa precisão as preferências dos usuários por determinados livros. ${ }^{16}$

Posteriormente, em 1997, a Google otimizou o modelo de negócio da Amazon, constatando uma forma mais eficiente de vender os produtos e serviços, qual seja: ranquear as páginas da web a partir de um sistema de busca inteligente ("Inteligência Artificial”). Esse sistema parte da ideia de responder as perguntas do usuário conforme os seus termos de busca de maneira que a primeira página deve corresponder exatamente às expectativas dos usuários. 0 desafio era justamente coletar informações suficientes sobre os usuários para atingir a relevância do resultado da pesquisa. Para tanto, engenhosamente, a Google desenvolveu uma série de aplicativos (Google Apps) que demandam o cadastro e, portanto, a identificação do usuário. Esta manobra foi crucial para o desenvolvimento e aprimoramento dos algoritmos de personalização. Atualmente, a Google consegue monitorar todos os comportamentos dos seus usuários, ainda que estes não estejam logados, a partir de informações sobre a localização da pessoa, por exemplo. ${ }^{17}$

Por fim, a rede social Facebook desenvolveu uma aplicação para viabilizar a postagem de conteúdos diversos, desde o quê o usuário almoçou até o quê e como ele está se sentindo. Esse modelo de negócio estava baseado na ideia de que quanto mais informações os usuários disponibilizavam, melhor seria a experiência deles na rede social. Munido destas informações, o Facebook desenvolveu um algoritmo que alimenta a página padrão do site, ou seja, o Feed de notícias principais (algoritmo conhecido como EdgeRank). Esse algoritmo trabalha com três fatores: afinidade, conteúdo e atualidade. ${ }^{18}$

O que essas empresas têm em comum? Todos os modelos de negócios evidenciam que a publicidade é algo muito lucrativo, porque de forma cada vez mais eficiente vendem-se produtos e serviços a partir de um sistema de algoritmos de personalização que identificam as preferências dos usuários.

No entanto, para estes modelos de negócios funcionarem precisam coletar, compartilhar, classificar e tantas outras atividades definidas como tratamento de dados pessoais consoante 0 inc. $X$ do art. $5^{\circ}$ da LGPD.

\footnotetext{
${ }^{16}$ PARISER, Eli. The filter bubble: how the new personalized web is changing what we read and how we think. Nova York: Penguin Book, 2011. pp. 25 - 30.

17 PARISER, Eli. The filter bubble: how the new personalized web is changing what we read and how we think. Nova York: Penguin Book, 2011. pp. 30 - 35.

18 PARISER, Eli. The filter bubble: how the new personalized web is changing what we read and how we think. Nova York: Penguin Book, 2011. pp. 35 - 40.
} 
ISSN 1981-3694

(DOI): $10.5902 / 1981369464767$

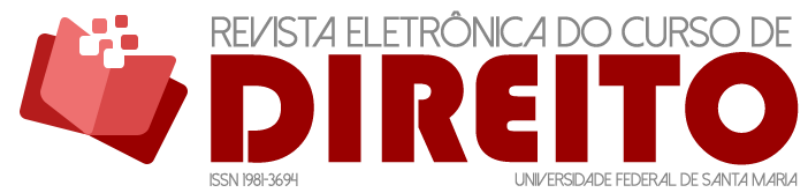

A PROTEÇ̃̃O DE DADOS PESSOAIS NO CONEXTO DA ECONOMIA INFORMACIONAL: DESAFIOS REGULATÓRIOS DO MARKETING COMPORTAMENTAL

CíNTIA Rosa PEREIRA DE LIMA

Assim, entende-se por marketing comportamental (Behavioral Targeting) um método de publicidade que utiliza informações sobre os clientes em potencial para otimizar as campanhas publicitárias. São alguns exemplos destas informações: o histórico de navegação e de compras. ${ }^{19}$

Em suma, a coleta massiva de dados pessoais dos consumidores viabiliza a oferta de produtos segmentados ou singularizados, levando em consideração os hábitos e os comportamentos dos consumidores, para quem a publicidade é dirigida de maneira personalizada (marketing "one-to-one"). ${ }^{20}$ Tal utilização dos dados pessoais motivou o que se denomina capitalismo de vigilância, em virtude do círculo vicioso: para se alcançar a relevância com base nos interesses dos consumidores, coletam-se informações de todo tipo sobre eles.

\subsection{Capitalismo de vigilância e a circulação transfronteiriça dos dados pessoais}

O capitalismo de vigilância estrutura-se a partir da coleta massiva de dados pessoais dos usuários das mais diversas aplicações da Internet. No entanto, para o seu correto funcionamento é fundamental que o usuário deixe rastros que possam identificá-lo assim como suas preferências. $O$ atual desenvolvimento tecnológico coloca em xeque o uso destes algoritmos de personalização, pois existirão tantos IPs conectando diversos objetos (Internet das Coisas), desde roupas, geladeiras, etiquetas de alimentos, até carros (os denominados “carros conectados"). Assim, outras novas técnicas serão desenvolvidas para monetizar todas estas informações, o que impõe um constante monitoramento por parte dos órgãos regulatórios, como a Autoridade Nacional de Proteção de Dados (ANPD).

Portanto, os capitalistas de vigilância, como as empresas acima citadas, devem repensar os respectivos modelos de negócios. Assim, observa-se uma busca constante em reorientar o “imperativo de predição", para continuar relevante ainda com o aumento de informações de forma exponencial.

Neste sentido, Shoshana Zuboff ${ }^{21}$ afirma que os gigantes do capitalismo de vigilância devem intensificar a competição para continuar lucrando no contexto dos novos mercados tendo

\footnotetext{
${ }^{19}$ NILL, Alexander; AALBERTS, Robert J. Legal and Ethical Challenges of Online Behavioral Targeting in Advertising. Journal of Current Issues \& Research in Advertising, vol. 35, issue 2, pp. 126 146. Disponível https://www.tandfonline.com/doi/pdf/10.1080/10641734.2014.899529?needAccess=true. Acesso em: 15 de fev. 2021.

${ }^{20}$ MENDES, Laura Schertel. Privacidade, proteção de dados e defesa do consumidor: linhas gerais de um novo direito fundamental. 2. Tiragem. São Paulo: Saraiva, 2019. pp. 88 - 89.

21 The Age of Surveillance Capitalism: the fight for a human future at the new frontier of power. Nova York: Public Affairs, 2019. p. 198.
} 
ISSN 1981-3694

(DOI): $10.5902 / 1981369464767$

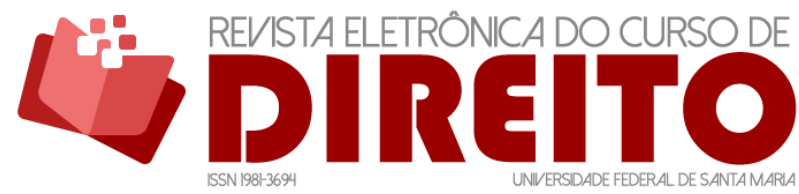

A PROTEÇÃO DE DADOS PESSOAIS NO CONEXTO DA ECONOMIA INFORMACIONAL: DESAFIOS REGULATÓRIOS DO MARKETING COMPORTAMENTAL

CíNTIA Rosa PEREIRA DE LIMA

em vista o comportamento futuro diante das novas tecnologias. Isto porque mesmo os processos mais sofisticados de conversão de comportamentos em lucro dependem da habilidade de prever o futuro com precisão, dependendo da matéria-prima disponível, que são as informações pessoais.

Entretanto, não é difícil imaginar que os capitalistas de vigilância já estão se antecipando, a fim de desenhar novos algoritmos de personalização que irão se adaptar às novas tecnologias que surgirão. Todavia, tal constatação pode aumentar ainda mais a vulnerabilidade e a assimetria entre estes capitalistas e os titulares de dados pessoais, acentuando sua hipervulnerabilidade. Por isso, as leis de proteção de dados, como a LGPD, devem estar em constante atualização para garantir a eficácia da autodeterminação informativa seja qual for a tecnologia aplicada.

Neste sentido, a LGPD não pretendeu esgotar o tema sobre proteção de dados; mas, antes, estrutura-se com base em princípios elencados no art. $6^{\circ}$ da LGPD, que deverão nortear a aplicação da lei diante dos avanços tecnológicos. Além disso, a própria Autoridade Nacional de Proteção de Dados (ANPD) tem a competência de editar normas e procedimentos sobre a proteção de dados (inc. II do art. 55-J), considerando a evolução destas tecnologias. Note-se, outrossim, a atuação preventiva da ANPD, que deverá fiscalizar os agentes de tratamento de dados, e impor as sanções previstas em lei na hipótese de descumprimento da LGPD (inc. VI do art. 55-J da LGPD) conforme a Resolução CD/ANPD n. 1, de 28 de outubro de 2021.

Diante da característica transfronteiriça da economia informacional, será importante a cooperação entre a ANPD e autoridades de proteção de dados pessoais de outros países conforme estabelecido no inc. XII do art. 55-J da LGPD²2. Além da atuação da ANPD, os próprios capitalistas de vigilância devem se conscientizar para consolidar boas práticas em matéria de proteção de dados pessoais para não correr o risco de legalmente inviabilizar suas atividades. 0 que se espera alcançar a partir da composição multissetorial do Conselho Nacional de Proteção de Dados Pessoais e da Privacidade (CNPDP) nos termos do art. 58-A da LGPD. ${ }^{23}$ Em outras palavras, este órgão consultivo da ANPD poderá contribuir conciliando os interesses e as

\footnotetext{
22 Vide: LIMA, Cíntia Rosa Pereira de; DE LUCCA, Newton. A necessária Convenção de Direito Privado na América Latina para a proteção dos dados pessoais. In: LIMA, Cíntia Rosa Pereira de (org.). PEROLI, Kelvin (rev.). Autoridade Nacional de Proteção de Dados (ANPD): desafios e perspectivas. São Paulo: Almedina, 2021. No prelo.

${ }^{23}$ Cf. BIONI, Bruno Ricardo; RIELLI, Mariana Marques. A construção multissetorial da LGPD: história e aprendizados. In: FRANCOSKI, Denise de Souza Luiz; TASSO, Fernando Antonio. A Lei Geral de Proteção de Dados Pessoais: aspectos práticos e teóricos relevantes no setor público e privado. São Paulo: Revista dos Tribunais, 2021. pp. 223 - 258. p. 225.
} 
ISSN 1981-3694

(DOI): $10.5902 / 1981369464767$

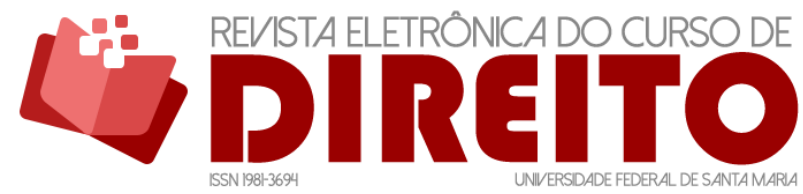

A PROTEÇÃO DE DADOS PESSOAIS NO CONEXTO DA ECONOMIA INFORMACIONAL: DESAFIOS REGULATÓRIOS DO MARKETING COMPORTAMENTAL

CíNTIA Rosa PEREIRA DE LIMA

necessidades dos diversos players do mercado informacional, sem esquecer do protagonista deste espetáculo, que é o titular de dados pessoais.

\subsection{Capitalismo informacional sustentável e os Códigos de Boas Práticas em matéria de proteção de dados}

Um dos grandes impasses da LGPD foi definir um modelo entre regulação, corregulação ou autorregulação. Vigorou o modelo de corregulação, entendida como formas de coordenação, ora iguais, ora hierárquicas, entre reguladores públicos e reguladores privados. Há muitas possibilidades de se concretizar, mas pode ser resumido na determinação de regras compartilhadas entre o Poder Público e os entes privados, bem como sua fiscalização. Em outras palavras, pode-se constatar a corregulação quando o Estado, por meio direto ou indireto, regula um determinado setor, sem excluir a possibilidade dos representantes de determinado setor estabelecerem as regras para se adequarem à LGPD. Em matéria de proteção de dados pessoais, sendo este um direito fundamental, questiona-se a possibilidade da autorregulação ou, mesmo, corregulação. $^{24}$

No entanto, tal possibilidade já tinha sido prevista na revogada Diretiva 95/46/CE, ao disciplinar os denominados “Códigos de Boas Práticas" no art. $27^{25}$, estabelecendo que as associações e outras organizações representativas de determinado setor poderão adotar normas deontológicas para implementar um padrão ético e legal para o tratamento de dados, sujeitas à apreciação da Autoridade de Proteção de Dados. Tendo em vista os resultados positivos desta prática, no GDPR (art. 40), estes Códigos de Boas Práticas assumiram claramente um instrumento de corregulação. ${ }^{26}$

Entende-se por "Códigos de Boas Práticas" os documentos normativos internos das empresas ou órgãos públicos cujo objeto é adequar as práticas da empresa ou do órgão público à

24 POPOLI, Anna Rita. Codici di condotta e certificazioni. In: FINOCCHIARO, Giusella (coord.). Il nuovo Regolamento europeo sulla privacy e sulla protezione dei dati personali. Torino: Zanichelli Editore, 2017. pp. 367 - 422. p. 372.

25 “CAPITULO V - CODIGOS DE CONDUTA: Artigo 27 1. Os Estados-membros e a Comissão promoverão a elaboração de códigos de conduta destinados a contribuir, em função das características dos diferentes sectores, para a boa execução das disposições nacionais tomadas pelos Estados-membros nos termos da presente directiva. 2. Os Estados-membros estabelecerão que as associações profissionais e as outras organizações representativas de outras categorias de responsáveis pelo tratamento que tenham elaborado projectos de códigos nacionais ou que tencionem alterar ou prorrogar códigos nacionais existentes, podem submetê-los à apreciação das autoridades nacionais."

26 POPOLI, Anna Rita. Codici di condotta e certificazioni. In: FINOCCHIARO, Giusella (coord.). II nuovo Regolamento europeo sulla privacy e sulla protezione dei dati personali. Torino: Zanichelli Editore, 2017. pp. 367 - 422. p. 395. 
ISSN 1981-3694

(DOI): $10.5902 / 1981369464767$

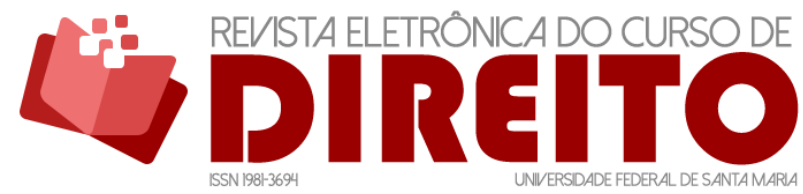

A PROTEÇÃO DE DADOS PESSOAIS NO CONEXTO DA ECONOMIA INFORMACIONAL: DESAFIOS REGULATÓRIOS DO MARKETING COMPORTAMENTAL

CíNTIA Rosa PEREIRA DE LIMA

lei de proteção de dados, esclarecendo as peculiaridades do tratamento dos dados daqueles que aderirem ao tratamento de dados mediante regras ou padrões específicos que permitam harmonizar os tratamentos de dados realizados, bem como facilitar o exercício dos direitos assegurados aos sujeitos. ${ }^{27}$

A LGPD (art. 50) prevê a possibilidade dos controladores e operadores adotarem:

Regras de boas práticas e de governança que estabeleçam as condições de organização, o regime de funcionamento, os procedimentos, incluindo reclamações e petições de titulares, as normas de segurança, os padrões técnicos, as obrigações específicas para os diversos envolvidos no tratamento, as ações educativas, os mecanismos internos de supervisão e de mitigação de riscos e outros aspectos relacionados ao tratamento de dados pessoais. ${ }^{28}$

No sistema brasileiro, todavia, estes “Códigos de Boas Práticas” não são preventivamente avalizados pela ANPD. No entanto, eles podem ser reconhecidos e divulgados pela ANPD conforme dispõe o $\S 3^{\circ}$ do art. $50 .{ }^{29}$ Assim, a ANPD tem competência de fiscalizar estes “Códigos de Boas Práticas", nos termos do art. 55-J, inc. IV da LGPD, podendo analisar se estão adequados ou não ao sistema de proteção de dados pessoais, e, consequentemente, fazer recomendações ou exigir adequações destes à LGPD.

Em suma, dada a natureza de direito fundamental que tem a proteção de dados pessoais $^{30}$, a ANPD deve adotar medidas cautelosas sobre o tema, verificando a adequação ou não dos “Códigos de Boas Práticas" adotados pelas empresas ou órgãos públicos. Vale ressaltar, ainda, que tal prática pode representar uma atenuante às sanções administrativas previstas no $\S$ $1^{\circ}$ do art. 52 da LGPD. Em outras palavras, os agentes de tratamento de dados podem demonstrar que têm uma sólida política de boas práticas e governança em matéria de proteção de dados, expressamente prevista no inciso IX do referido dispositivo legal, fator que poderá ser levado em consideração pela ANPD ao impor as sanções previstas em lei.

\footnotetext{
27 SALOM, Javier Aparicio. Estudio sobre la Protección de Datos. 4. ed. Cizur Menor (Navarra): Editorial Aranzadi - Thomson Reuters, 2013. p. 198.

${ }^{28}$ BRASIL. Lei n 13.709 de 14 de agosto de 2018. Lei Geral de Proteção de Dados Pessoais (LGPD). In: Diário Oficial da República Federativa do Brasil, Brasília, DF, 15 ago. 2018.

${ }_{29}^{2}$ LIMA, Cíntia Rosa Pereira de. Autoridade Nacional de Proteção de Dados e a Efetividade da Lei Geral de Proteção de Dados. São Paulo: Almedina, 2020. p. 229.

30 BRASIL. SUPREMO TRIBUNAL FEDERAL. Julgamento das Medidas Cautelares nas Ações Diretas de Inconstitucionalidade 6387, 6388, 6389, 6390 e 6393. Disponível em: https: / / jurisprudencia.stf.jus.br/pages/search?base=acordaos\&pesquisa_inteiro_teor=false\&sinonimo=tru

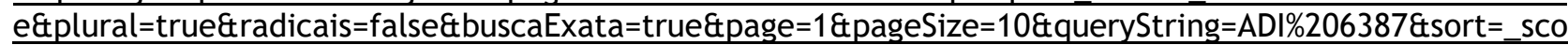
re\&sortBy=desc. Acesso em: 30 de jan. 2021.
} 


\section{OS PERIGOS DOS PERFIS CONSTRUÍDOS DE MANEIRA AUTOMATIZADA}

Conforme se constatou, toda a atividade de marketing comportamental se desenvolve a partir do tratamento de dados pessoais por algoritmos de personalização que identificam um perfil para o usuário para que se possa sugerir produtos e serviços conforme sua preferência. Neste sentido, Hildebrandt alerta para o fato do conceito de "profiling" ser um conceito em construção, em sentido amplo, é considerado como um processo de descobrir correlações das informações constantes na base de dados a fim de identificar e representar uma pessoa humana. ${ }^{31}$

O Regulamento Geral de Proteção de Dados da União Europeia - GDPR (2016/679) prevê expressamente um conceito para tal prática no artigo 4(4), garantindo a possibilidade de oposição ao tratamento de dados para finalidades de marketing direto (art. 21) ${ }^{32}$ e a não sujeição do titular dos dados às decisões automatizadas como o profiling (art. 22) ${ }^{33}$.

${ }^{31}$ HILDEBRANDT, Mireille. Defining Profiling: A New Type of Knowledge? In: HILDEBRANDT, M.; GUTWIRTH, S. (Eds.) Profiling the European Citizen: Cross-Disciplinary Perspectives. Cham/SWI: Springer Science, 2008, p. 19.

32 "Section 4 - Right to object and automated individual decision-making. Article 21 - Right to object. 1. The data subject shall have the right to object, on grounds relating to his or her particular situation, at any time to processing of personal data concerning him or her which is based on point $(e)$ or $(f)$ of Article 6(1), including profiling based on those provisions. The controller shall no longer process the personal data unless the controller demonstrates compelling legitimate grounds for the processing which override the interests, rights and freedoms of the data subject or for the establishment, exercise or defence of legal claims. 2. Where personal data are processed for direct marketing purposes, the data subject shall have the right to object at any time to processing of personal data concerning him or her for such marketing, which includes profiling to the extent that it is related to such direct marketing. 3 . Where the data subject objects to processing for direct marketing purposes, the personal data shall no longer be processed for such purposes. 4. At the latest at the time of the first communication with the data subject, the right referred to in paragraphs 1 and 2 shall be explicitly brought to the attention of the data subject and shall be presented clearly and separately from any other information. 5 . In the context of the use of information society services, and notwithstanding Directive 2002/58/EC, the data subject may exercise his or her right to object by automated means using technical specifications. 6 . Where personal data are processed for scientific or historical research purposes or statistical purposes pursuant to Article 89(1), the data subject, on grounds relating to his or her particular situation, shall have the right to object to processing of personal data concerning him or her, unless the processing is necessary for the performance of a task carried out for reasons of public interest."

33 UNIÃO EUROPEIA. Regulation (EU) 2016/679 of the European Parliament and of the Council of 27 April 2016 on the protection of natural persons with regard to the processing of personal data and on the free movement of such data, and repealing Directive 95/46/EC (General Data Protection Regulation). Disponível em: https://eur-lex.europa.eu/eli/reg/2016/679/oj. Acesso em: 10 de fev. 2021. "Article 22 - Automated individual decision-making, including profiling 1. The data subject shall have the right not to be subject to a decision based solely on automated processing, including profiling, which produces legal effects concerning him or her or similarly significantly affects him or her. 2. Paragraph 1 shall not apply if the decision: (a) is necessary for entering into, or performance of, a contract between the data subject and a data controller; $(b)$ is authorized by Union or Member State law to which the controller is subject and which also lays down suitable measures to safeguard the data subject's rights 
ISSN 1981-3694

(DOI): $10.5902 / 1981369464767$

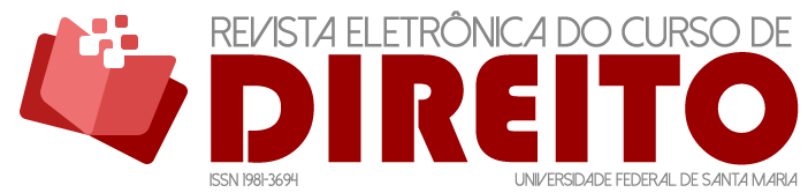

A PROTEÇÃO DE DADOS PESSOAIS NO CONEXTO DA ECONOMIA INFORMACIONAL: DESAFIOS REGULATÓRIOS DO MARKETING COMPORTAMENTAL

CíNTIA Rosa PEREIRA DE LIMA

Preliminarmente, deve-se compreender o que significa a expressão “online profiling”, genericamente considerado um processo de coleta, mineração e correlação de dados pessoais de um usuário, resultando em um perfil (profile) daquele indivíduo, qualificando-o e categorizandoo a partir dos sites que visita, dos likes e dislikes em uma determinada rede social, dos aplicativos utilizados, dos termos de busca numa determinada ferramenta de busca, etc. Segundo Frederik Borgesius ${ }^{34}$ esse processo seria construído com base no monitoramento do comportamento do usuário na Internet com objetivo de enviar publicidade direcionada aos interesses detectados com base neste monitoramento (marketing comportamental).

Os riscos desta prática é a doutrinação do indivíduo com base nesse perfil, segundo o diagnóstico de Eli Pariser ${ }^{35}$ de que se cria um "filtro invisível” (uma bolha) afetando na própria interação deste indivíduo com outras pessoas e no acesso à informação. Além disso, há um risco à privacidade e à proteção de dados na medida em que o histórico do comportamento do indivíduo é vasculhado sem que se tenha conhecimento para poder consentir ou não.

Muito embora a LGPD não tenha trazido uma definição para “perfiliação", este tema foi mencionado no parágrafo $2^{\circ}$ do art. 12 da LGPD que confirma ser dados pessoais aqueles utilizados para a construção do perfil comportamental da pessoa natural identificada. Não restando dúvidas de ser aplicada a LGPD a tais práticas. Assim, para evitar os inconvenientes acima mencionados, a LGPD assegura ao titular o direito de rever as decisões tomadas unicamente com base em tratamento automatizado de dados pessoais que afetem seus interesses (art. 20), para tanto, o controlador deve fornecer, sempre que solicitadas, informações claras e adequadas sobre os critérios e os procedimentos utilizados para a decisão automatizada ( $\$ 1^{\circ}$ do art. 20 da LGPD).

Alguns pressupostos devem ser observados, a saber: tratamento automatizado de dados pessoais, ou seja, sem a participação humana; impacto nos interesses da pessoa, isto é,

and freedoms and legitimate interests; or (c) is based on the data subject's explicit consent. 3. In the cases referred to in points (a) and (c) of paragraph 2, the data controller shall implement suitable measures to safeguard the data subject's rights and freedoms and legitimate interests, at least the right to obtain human intervention on the part of the controller, to express his or her point of view and to contest the decision. 4. Decisions referred to in paragraph 2 shall not be based on special categories of personal data referred to in Article 9(1), unless point (a) or (g) of Article 9(2) applies and suitable measures to safeguard the data subject's rights and freedoms and legitimate interests are in place."

${ }^{34}$ BORGESIUS, Frederik Zuiderveen. Behavioral targeting: A european legal perspective. IEEE Security \& Privacy, vol.11, no. 1, Jan.-Feb. 2013. p. 82: "Behavioral targeting, or online profiling, is a hotly debated topic. (...) Behavioral targeting is the monitoring of people's online behavior over time to use the collected information to target people with advertising matching their inferred interests."

35 PARISER, Eli. The filter bubble: how the new personalized web is changing what we read and how we think. Nova York: Penguin Book, 2011. passim. 
ISSN 1981-3694

(DOI): $10.5902 / 1981369464767$

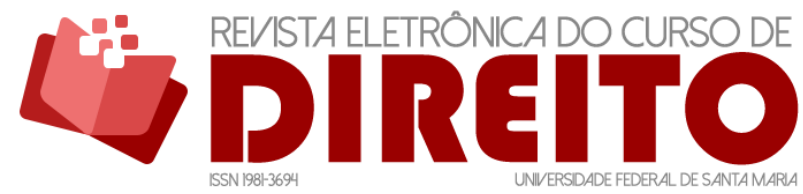

A PROTEÇÃO DE DADOS PESSOAIS NO CONEXTO DA ECONOMIA INFORMACIONAL: DESAFIOS REGULATÓRIOS DO MARKETING COMPORTAMENTAL

CíNTIA Rosa PEREIRA DE LIMA

informações que direta ou indiretamente possa afetar os interesses dos titulares de dados; e, a finalidade que é a definição do perfil pessoal, profissional, de consumo ou de crédito. ${ }^{36}$

Uma questão a ser colocada é se o controlador deverá fornecer ou não estas informações, pois o $\$ 1^{\circ}$ do art. 20 da LGPD ressalva os segredos comercial e industrial. Entendemos que a LGPD garante este direito aos titulares de dados, portanto, o controlador deverá obrigatoriamente informar de forma clara e adequada os critérios e os procedimentos utilizados para a construção do perfil do titular de dados. A ressalva referente à proteção dos segredos comercial e industrial deve ser excepcionalmente considerados, na medida em que é possível sim cumprir este direito sem que represente um prejuízo ao modelo de negócio do controlador.

Tanto é assim que o $\$ 2^{\circ}$ do art. 20 da LGPD determina que ao não fornecer tais informações, o controlador se sujeita à auditoria determinada pela ANPD a fim de verificar aspectos discriminatórios no tratamento automatizado de dados pessoais em questão (art. 55-J, inc. $V$ da LGPD). Observe-se, portanto, que o não cumprimento deste direito pode expor ainda mais o modelo de negócio do controlador. ${ }^{37}$

\section{A ATUAÇÃO dA AUTORIDADE NACIONAL DE PROTEÇÃO DE DADOS PESSOAIS PARA UMA ECONOMIA INFORMACIONAL SUSTENTÁVEL}

Diante de tudo que foi exposto, constata-se que a atuação da Autoridade Nacional de Proteção de Dados Pessoais (ANPD) será fundamental para a efetiva proteção dos titulares de dados diante das práticas de online profiling e marketing comportamental. ${ }^{38} 0$ objetivo desta atuação não é criar entraves ao desenvolvimento econômico, mas reequilibrar os interesses envolvidos dada a dinâmica do capitalismo informacional em que os dados pessoais são verdadeiras commodities.

36 HOSNI, David Salim Santos; MARTINS, Pedro Bastos Logo. Automated Decision-making and Data Protection Regulation: alternatives presented by the Brazilian General Data Protection Law. In: PARENTONI, Leonardo; CARDOSO, Renato César (orgs.) Law, Technology and Innovation. Vol. II: insights on Artificial Intelligence and the Law. Belo Horizonte (MG), 2021. pp. 150 - 187. p. 163.

37 LIMA, Cíntia Rosa Pereira de; RAMIRO, Lívia Froner Moreno. Direitos do Titular dos Dados Pessoais. In: LIMA, Cíntia Rosa Pereira de. Comentários à Lei Geral de Proteção de Dados. São Paulo: Almedina, 2020. pp. 249 - 278. p. 273.

${ }^{38}$ Cf. PARENTONI, Leonardo. Autoridade Nacional de Proteção de Dados brasileira: uma visão otimista.

Revista do Advogado, Lei Geral de Proteção de Dados, ano XXXIX, n. 144, nov., 2019. pp. 209 - 219. p. 212. 
Ainda que esta atuação seja difícil, não poderá ser impossível. 0 setor bancário é regulado, assim como as atividades de credit scoring, por que não seria o setor de marketing comportamental? Frank Pasquale adverte:

Cada um desses movimentos teve algumas pequenas vitórias ao longo dos anos. Mas não é suficiente apenas observar as principais empresas controlando nossas informações, nossa mídia e nosso destino financeiro. Temos que ser capazes de aprimorá-los e aprimorá-los. Além disso, precisamos aproveitar os sucessos em uma área como modelos para o resto da sociedade da caixa preta. Se as pontuações de crédito podem ser regulamentadas, por que não os sistemas de pontuação usados por anunciantes e empregadores digitais? [tradução livre] ${ }^{39}$

Conforme o inc. I do art. 55-J da LGPD, compete à ANPD zelar pela proteção dos dados pessoais. Uma vez constatado que a matéria-prima do marketing comportamental são dados pessoais, pois são informações que identificam ou podem identificar o titular nos termos do art. $5^{\circ}$, inc. I c/c $\S 2^{\circ}$ do art. 12 da LGPD, a ANPD deverá regular tal atividade, além de fiscalizar as atividades dos agentes de tratamento de dados envolvidos no marketing comportamental.

Nota-se, recentemente, a ANPD aprovou o Regulamento do Processo de Fiscalização e do Processo Administrativo Sancionador (Resolução CD/ANPD n. 1, de 28 de outubro de 2021), e determina que a atividade de fiscalização compreende as atividades de monitoramento, orientação e atuação preventiva (art. $2^{\circ}$ desta Resolução). Desta definição, constata-se a ênfase preventiva e responsiva da ANPD, ou seja, o objetivo principal desta fiscalização é constatar eventuais práticas contrárias à LGPD para orientar os agentes de tratamento sobre a forma mais adequada de aplicar os procedimentos de tratamento automatizado de dados pessoais para a construção de perfis. ${ }^{40}$

Neste procedimento de fiscalização, o controlador deverá fornecer cópia de documentos (físicos ou digitais), bem como os dados e informações relevantes para a avaliação

39 "Each of these movements has had some small victories over the years. But it's not enough just to watch the key firms controlling our information, our media, and our financial fates. We have to be able to improve them and the ways that they go about their business. Moreover, we need to build on successes in one area as models for the rest of the black box society. If credit scores can be regulated, why not the scoring systems used by digital advertisers and employers?" The Black Box Society: the secret algorithms that control money and information. Cambridge: Harvard University Press, 2015. p. 140.

${ }^{40}$ Neste sentido, a Resolução distingue, no art. 15, atividade de monitoramento, que é o levantamento de informações relevantes para subsidiar as decisões da ANPD $\left(\S 1^{\circ}\right)$; atividade de orientação, caracterizada pela economicidade e orientação, conscientização e educação dos agentes de tratamento de dados e dos titulares de dados $\left(\$ 2^{\circ}\right)$; atividade preventiva, que é a "construção conjunta e dialogada de soluções e medidas que visam a reconduzir o agente de tratamento à plena conformidade ou a evitar ou remediar situações que possam acarretar risco ou dano aos titulares de dados pessoais e a outros agentes de tratamento." 
ISSN 1981-3694

(DOI): $10.5902 / 1981369464767$

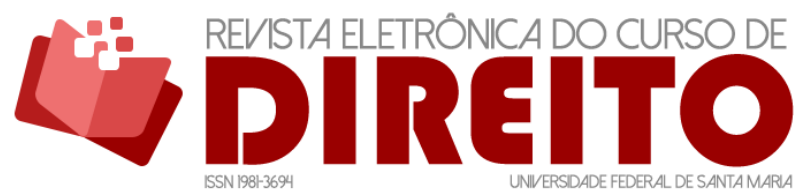

A PROTEÇÃO DE DADOS PESSOAIS NO CONEXTO DA ECONOMIA INFORMACIONAL: DESAFIOS REGULATÓRIOS DO MARKETING COMPORTAMENTAL

das atividades de tratamento de dados pessoais (inc. I do art. $5^{\circ}$ da Resolução CD/ANPD n. 1, de 28 de outubro de 2021). O problema das tecnologias disruptivas como a Inteligência Artificial é a impossibilidade ou elevada dificuldade de serem auditadas, tendo em vista o constante aprendizado, que segue o programado, mas vai muito além do previsto muitas vezes. Neste sentido, não basta disponibilizar tais informações, mas a ANPD deve ter condições técnicas e servidores habilitados para saber como realizar tais auditorias e interpretar os documentos disponibilizados pelo controlador.

\section{CONCLUSÃO}

Ter uma Lei Geral de Proteção de Dados Pessoais não é o bastante para assegurar o enforcement do direito fundamental à proteção de dados pessoais. Para além de uma lei sobre o tema, deve-se estabelecer ferramentas para a concretização deste direito em diversos cenários, inclusive no "capitalismo de vigilância" e do marketing comportamental. Neste sentido, importante notar que a LGPD é propositalmente principiológica a fim de se adequar ao desenvolvimento econômico e tecnológico. Cabendo à ANPD monitorar, fiscalizar, orientar para que a LGPD seja efetivamente cumprida.

A partir das características da economia informacional, cuja produtividade e competitividade depende da capacidade de gerar, processar e aplicar de forma eficiente as informações, constatou-se que os algoritmos de personalização são exemplos cristalinos em que se transformam as curtidas, não-curtidas, compartilhamentos e etc. em valiosas informações sobre predileções e tendências dos usuários das mais diversas aplicações de Internet. Desta forma, o grande desafio à efetiva proteção de dados pessoais é equacionar os interesses em jogo, de um lado a legítima busca por lucros no desenvolvimento de seu negócio; de outro, a proteção do titular de dados pessoais, garantido ferramentas para sua autodeterminação informativa.

A partir da Resolução CD/ANPD n. 1, de 28 de outubro de 2021, pode-se perceber claramente que a atuação da ANPD tem como ponto de partida a atuação de forma responsiva, a fim de estimular a adoção de medidas pelos agentes de tratamento de dados em conformidade com a LGPD. Além disso, busca-se com tal atuação o estímulo à promoção da cultura de proteção de dados pessoais, dentre outras premissas previstas no art. 17 da referida Resolução.

Neste contexto, a atuação multissetorial apresenta-se uma alternativa muito interessante para chegar a este equilíbrio, desde que encarada com responsabilidade. Assim, os 
ISSN 1981-3694

(DOI): $10.5902 / 1981369464767$

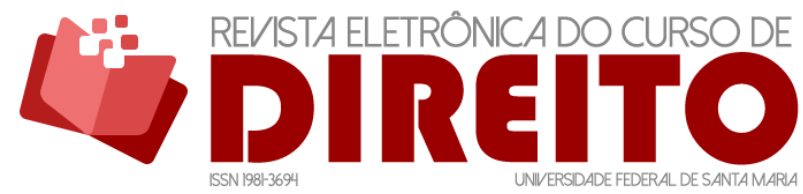

A PROTEÇÃO DE DADOS PESSOAIS NO CONEXTO DA ECONOMIA INFORMACIONAL: DESAFIOS REGULATÓRIOS DO MARKETING COMPORTAMENTAL

CíNTIA Rosa PEREIRA DE LIMA

agentes de tratamento de dados devem estabelecer algumas regras deontológicas nos "Códigos de Boas Práticas", observando os princípios (art. $6^{\circ}$ da LGPD), bem como as bases legais para o tratamento de dados elencadas no art. $7^{\circ}$ (dados pessoais) e no art. 11 (dados pessoais sensíveis).

Os "Códigos de Boas Práticas" não são aprovados previamente pela ANPD, mas ela poderá analisá-los ao realizar auditorias a partir das reclamações dos titulares de dados nos termos do art. 55-J, inc. V da LGPD ou quando entender necessário nos termos dos incisos IV e XVI do art. 55-J da LGPD. Esses seriam alguns exemplos da atuação fiscalizatória da ANPD. Mas, também, a ANPD tem competência de editar regulamentos e procedimentos sobre proteção de dados pessoais e privacidade consoante o inc. XIII do art. 55-J da LGPD ("poder-dever" regulatório).

0 art. 20 da LGPD garante aos titulares de dados o direito a rever as decisões automatizadas que afetem seus interesses e destinadas à criação de perfil pessoal, profissional de consumo ou de crédito. Este direito deve constar nos Códigos de Boas Práticas, para que os agentes de tratamento de dados possam de forma transparente, indicar os critérios e procedimentos utilizados no tratamento automatizado de dados pessoais de maneira genérica. Além disso, recebendo um pedido individual de um titular de dados, o controlador deve observar e informar de forma clara e adequada, não podendo se furtar a este direito sob o fundamento dos segredos comercial e industrial. Esta hipótese deve ser excepcional, e não é conveniente ao controlador porque atrai a auditoria da ANPD o que pode expor ainda mais o modelo de negócio do controlador.

Conclui-se que a efetiva proteção de dados pessoais diante da utilização massiva de dados pessoais para fins de marketing comportamental pode ser atingida desde que consolidada em “Códigos de Boas Práticas" que enfrentem o tema, além de uma regulação específica sobre a matéria e a fiscalização eficiente por parte da Autoridade Nacional de Proteção de Dados.

\section{REFERÊNCIAS}

BARLOW, John Perry. The Next: Economy of Ideas. Wired 8.10. Disponível em: https://www.wired.com/2000/10/download/. Acesso em: 12 de fev. 2021.

BASTOS, Marco T; MERCEA, Dan. The Brexit Botnet and User-Generated Hyperpartisan News. Social Science Computer Review, vol. 37, issue 1, 2019. Disponível em: https://journals.sagepub.com/doi/pdf/10.1177/0894439317734157. Acesso em: 15 de fev. 2021. 
BORGESIUS, Frederik Zuiderveen. Behavioral targeting: A european legal perspective. IEEE Security \& Privacy, vol. 11, no. 1, Jan./Feb. 2013.

BRASIL. Autoridade Nacional de Proteção de Dados (ANPD). Resolução CD/ANPD n. 1, de 28 de outubro de 2021. Aprova o Regulamento do Processo de Fiscalização e do Processo Administrativo Sancionador no âmbito da Autoridade Nacional de Proteção de Dados. Disponível em: https://www.in.gov.br/web/dou/-/resolucao-cd/anpd-n-1-de-28-de-outubro-de-2021355817513. Acesso em: 06 de nov. 2021.

BRASIL. Lei no 13.709 de 14 de agosto de 2018. Lei Geral de Proteção de Dados Pessoais (LGPD). In: Diário Oficial da República Federativa do Brasil, Brasília, DF, 15 ago. 2018.

BRASIL. SUPERIOR TRIBUNAL DE JUSTIÇA. REsp 1186616/MG, Rel. Ministra NANCY ANDRIGHI, TERCEIRA TURMA, julgado em 23/08/2011, DJe 31/08/2011.

BRASIL. SUPREMO TRIBUNAL FEDERAL. Julgamento das Medidas Cautelares nas Ações Diretas de Inconstitucionalidade 6387, 6388, 6389, 6390 e 6393. Disponível em:

https: / / jurisprudencia.stf.jus.br/pages/search?base=acordaos\&pesquisa_inteiro_teor=false\&sino nimo=true\&plural=true\&radicais=false\&buscaExata=true\&page=1\&pageSize=10\&queryString=ADI\% 206387\&sort=_score\&sortBy=desc. Acesso em: 30 de jan. 2021.

BIONI, Bruno Ricardo; RIELLI, Mariana Marques. A construção multissetorial da LGPD: história e aprendizados. In: FRANCOSKI, Denise de Souza Luiz; TASSO, Fernando Antonio. A Lei Geral de Proteção de Dados Pessoais: aspectos práticos e teóricos relevantes no setor público e privado. São Paulo: Revista dos Tribunais, 2021. pp. 223 - 258.

CASTELLS, Manuel. The rise of the network society: the information age: economy, society and culture. Cornwall: Blackwell Publishers, 2000. V. 1.

FULLER, Greice Patricia; LOPEZ, José Luiz Bátiz. Empresa, Drechos Humanos y Sociedad de la Información. Revista Eletrônica do Curso de Direito da Universidade Federal de Santa Maria, vol. 14, n. 2, e33710, maio./ago. 2019. ISSN 1981-3694. DOI:

http://dx.doi.org/10.5902/1981369433710 . Disponível em:

https://periodicos.ufsm.br/revistadireito/article/view/33710 Acesso em: 15 de fev. 2021.

GREWAL, Paul. Suspending Cambridge Analytica and SCL Group from Facebook. Facebook Newsroom, 16 março 2018. Disponível em:

https://newsroom.fb.com/news/2018/03/suspending-cambridge-analytica/ . Acesso em: 15 de fev. 2021.

HILDEBRANDT, Mireille. Defining Profiling: A New Type of Knowledge? In: HILDEBRANDT, M.; GUTWIRTH, S. (Eds.) Profiling the European Citizen: Cross-Disciplinary Perspectives.

Cham/SWI: Springer Science, 2008.

HOSNI, David Salim Santos; MARTINS, Pedro Bastos Logo. Automated Decision-making and Data Protection Regulation: alternatives presented by the Brazilian General Data Protection Law. In: PARENTONI, Leonardo; CARDOSO, Renato César (orgs.) Law, Technology and Innovation. Vol. II: insights on Artificial Intelligence and the Law. Belo Horizonte (MG), 2021. pp. 150 - 187. 
LIMA, Cíntia Rosa Pereira de Lima; PEROLI, Kelvin. Direito Digital: compliance, regulação e governança. São Paulo: Quartier Latin, 2019.

LIMA, Cíntia Rosa Pereira de; DE LUCCA, Newton. A necessária Convenção de Direito Privado na América Latina para a proteção dos dados pessoais. In: LIMA, Cíntia Rosa Pereira de (org.). PEROLI, Kelvin (rev.). Autoridade Nacional de Proteção de Dados (ANPD): desafios e perspectivas. São Paulo: Almedina, 2021. No prelo.

LIMA, Cíntia Rosa Pereira de; RAMIRO, Lívia Froner Moreno. Direitos do Titular dos Dados Pessoais. In: LIMA, Cíntia Rosa Pereira de. Comentários à Lei Geral de Proteção de Dados. São Paulo: Almedina, 2020. pp. 249 - 278. p. 273.

LIMA, Cíntia Rosa Pereira de. Autoridade Nacional de Proteção de Dados e a Efetividade da Lei Geral de Proteção de Dados. São Paulo: Almedina, 2020. p. 47.

MENDES, Laura Schertel. Privacidade, proteção de dados e defesa do consumidor: linhas gerais de um novo direito fundamental. 2. Tiragem. São Paulo: Saraiva, 2019. pp. 88 - 89.

MURRAY, Andrew. Information Technology Law: the law and society. Oxford: Oxford University Press, 2010.

NILL, Alexander; AALBERTS, Robert J. Legal and Ethical Challenges of Online Behavioral Targeting in Advertising. Journal of Current Issues \& Research in Advertising, vol. 35, issue 2, pp. 126 - 146. Disponível em:

https://www.tandfonline.com/doi/pdf/10.1080/10641734.2014.899529?needAccess=true.

Acesso em: 15 de fev. 2021.

PARENTONI, Leonardo. Autoridade Nacional de Proteção de Dados brasileira: uma visão otimista. Revista do Advogado, Lei Geral de Proteção de Dados, ano XXXIX, n. 144, nov., 2019. pp. 209 219.

PARISER, Eli. The filter bubble: how the new personalized web is changing what we read and how we think. Nova York: Penguin Book, 2011.

PASQUALE, Frank. The Black Box Society: the secret algorithms that control money and information. Cambridge: Harvard University Press, 2015.

POPOLI, Anna Rita. Codici di condotta e certificazioni. In: FINOCCHIARO, Giusella (coord.). II nuovo Regolamento europeo sulla privacy e sulla protezione dei dati personali. Torino: Zanichelli Editore, 2017. pp. 367 - 422.

ROUSE, Margaret. What Is Machine Learning. WHATIS.COM. Disponível em: https://searchenterpriseai.techtarget.com/definition/machine-learning-ML. Acesso em: 10 de fev. 2021.

SALOM, Javier Aparicio. Estudio sobre la Protección de Datos. 4. ed. Cizur Menor (Navarra): Editorial Aranzadi - Thomson Reuters, 2013.

UNIÃO EUROPEIA. Regulation (EU) 2016/679 of the European Parliament and of the Council of 27 April 2016 on the protection of natural persons with regard to the processing of personal 
A PROTEÇÃO DE DADOS PESSOAIS NO CONEXTO DA ECONOMIA INFORMACIONAL: DESAFIOS REGULATÓRIOS DO MARKETING COMPORTAMENTAL

Cíntia Rosa Pereira de Lima

data and on the free movement of such data, and repealing Directive 95/46/EC (General Data Protection Regulation). Disponível em: https://eur-lex.europa.eu/eli/reg/2016/679/oj. Acesso em: 10 de fev. 2021.

ZUBOFF, Shoshana. The Age of Surveillance Capitalism: the fight for a human future at the new frontier of power. Nova York: Public Affairs, 2019.

Recebido em: 14.03.2021 / Aprovado em: 25.11.2021 / Publicado em: 31.11.2021

\section{COMO FAZER REFERÊNCIA AO ARTIGO (ABNT):}

LIMA, Cíntia Rosa Pereira de. A proteção de dados pessoais no contexto da economia informacional: desafios regulatórios do marketing comportamental. Revista Eletrônica do Curso de Direito da UFSM, Santa Maria, RS, v. 16, n. 2, e64767, maio/ago. 2021. ISSN 1981-3694. DOI: http://dx.doi.org/10.5902/1981369464767. Disponível em: https://periodicos.ufsm.br/revistadireito/article/view/64767. Acesso em: dia mês. ano.

Direitos autorais 2021 Revista Eletrônica do Curso de Direito da UFSM

Editores responsáveis: Rafael Santos de Oliveira e Angela Araujo da Silveira Espindola

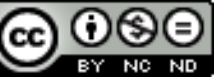

Esta obra está licenciada com uma Licença Creative Commons Atribuição-NãoComercial-SemDerivações 4.0 Internacional.

\section{SOBRE A AUTORA}

\section{Cíntia Rosa Pereira de LIMA}

Livre-Docência em Direito Civil Existencial e Patrimonial pela Faculdade de Direito de Ribeirão Preto (USP). Pós Doutora em Direito Civil na Università degli Studi di Camerino (Itália) com fomento CAPES (2014 - 2015). Doutora em Direito Civil pela Faculdade de Direito da USP (2004 - 2009) com estágio na Universidade de Ottawa (Canadá) com bolsa CAPES - PDEE Doutorado Sanduíche. Graduada pela Faculdade de Direito pela Universidade Estadual Paulista Júlio de Mesquita Filho UNESP (2002). Advogada, Membro da Comissão de Direito Digital da OAB de Ribeirão Preto. Líder do Grupo de Pesquisa: Observatório da LGPD (http://dgp.cnpq.br/dgp/espelhogrupo/4485179444454399) e do Grupo de Pesquisa: Observatório do Marco Civil da Internet no Brasil (http://dgp.cnpq.br/dgp/espelhogrupo/2215582162179038). Presidente do Instituto Avançado de Proteção de Dados (IAPD) e Pesquisadora do Programa Ano Sabático do IEA-RP (fev. a ago 2020). Coordenadora do Grupo de Estudos "Direito e Tecnologia" (Tech Law) do IEA-RP (2020 - atual). 